\title{
ВЛИЯНИЕ ПАНДЕМИИ COVID-19 НА СОЦИАЛЬНО-ЭКОНОМИЧЕСКОЕ РАЗВИТИЕ И ПОЛОЖЕНИЕ НАИБОЛЕЕ УЯЗВИМОГО НАСЕЛЕНИЯ
}

\author{
Барышева Галина Анзельмовна', \\ ganb@tpu.ru \\ Антипанова Ольга Андреевна1, \\ antipanova2020@gmail.com \\ Бинь Дао Тхань², \\ binh.daothanh@hust.edu.vn
}

\author{
${ }^{1}$ Национальный исследовательский Томский политехнический университет, \\ Россия, 634050, Томск, пр. Ленина, 30 \\ 2 Ханойский университет науки и технологий, \\ Вьетнам, 00084, Ханой, ул. Дай Ко Вьет, 1
}

\begin{abstract}
Барышева Галина Анзельмовна, доктор экономических наук, профессор Школы инженерного предпринимательства Национального исследовательского Томского политехнического университета; руководитель Международной научно-образовательной лаборатории технологий улучшения благополучия пожилых людей Национального исследовательского Томского политехнического университета.
\end{abstract}

Антипанова Ольга Андреевна, аспирант, лаборант Международной научно-образовательной лаборатории технологий улучшения благополучия пожилых людей Национального исследовательского Томского политехнического университета.

Бинь Дао Тхань, Ph.D., доцент школы экономики и менеджмента Ханойского университета науки и технологий.

Представлен обзор и анализ экономических последствий для экономических субъектов явления пандемии COVID-19. Цель - обоснование необходимости изменения политик в контексте непредсказуемых социально-экономических колебаний и долгосрочных последствий пандемии для людей. Методы: метод описательной статистики (обработка эмпирических данных, их систематизация и представление в форме графиков и таблии, описание посредством статистических показателей) на выборках прогнозных значений экономических потерь от пандемии в виде изменения роста валового внутреннего продукта (ВВП), данных Международного валютного фонда (2020). Использовались российские статистические и периодические источники. Сравнительный метод применялся для определения разницы между ростом ВВП и другими экономическими показателями за тот же период, методы синтеза и анализа данных - для выяснения статуса и взаимозависимости отраслей и услуг в процессе глобализации с использованием эмпирического исследований, посвященных данной теме. Результаты. Определены финансовые меры, направленные на поддержку предприятий и организаций, а также наиболее уязвимых категорий населения, прежде всего старших возрастных групп. Основными предпринимаемыми мерами помощи выступают: распределение продовольствия, выплата социальных пособий, поддержка новых режимов занятости, медицинское обслуживание, создание условий для снижения риска заражения инфекцией. На макроуровне определены новые сильные стороны проводимых мероприятий для включения их в политику развития, направленную на предотвращение и контроль пандемии, пересмотр налоговой нагрузки, преодоление кризиса и содействие социально-экономическому развитию в будущем.

Ключевые слова: Пандемия COVID-19, меры помощи, уязвимые слои населения, цепочка поставок, рынок труда, безработица, заработная плата, социальные льготы, уязвимые группы, пожилые люди. 


\section{Введение}

Явление пандемии COVID-19, распространяющейся по всему миру, оказывает значительное влияние на вовлеченность населения в социально-экономическую жизнь и экономический рост, вызывая непредсказуемые человеческие и экономические потери. По состоянию на 15 ноября 2020 года в мире зарегистрировано более 53 млн случаев коронавирусной инфекции и более 1,3 млн смертей [1]. Тревожные статистические показатели COVID-19 выявлены в России: за весь период насчитывается 1925825 заболевших в 85 регионах, скончалось 33186 человек. Доля пожилых людей среди умерших превышает 80 \%. Россия находится на пятом месте (после США, Бразилии, Индии и Франции) в мировом рейтинге Пандемиады-2020 [2]. Полное или частичное сокращение занятости в мире во втором квартале 2020 г. эквивалентно потере 400 млн рабочих мест [3].

Страны по всему миру предпринимают меры поддержки группам населения, которые в период пандемии оказались наиболее уязвимыми слоями населения. К ним в первую очередь относятся пожилые люди, как правило, имеющие хронические заболевания, а также работники сферы здравоохранения и других жизненно важных услуг. $\mathrm{C}$ наступлением пандемии сильнее всего изменилась жизнь изолированно проживающих людей и людей, находящихся в пансионатах. Основные предпринимаемые меры помощи: распределение продовольствия, выплата социальных пособий, поддержка занятости, медицинское обслуживание, создание условий для снижения риска заражения инфекцией.

В исследовании использовались методология комплексного подхода для изучения воздействия пандемии COVID-19 на экономику России и других стран, оценки социально-экономических последствий с использованием данных и их анализа из опубликованных материалов МВФ и российских статистических, периодических и новостных источников. Сравнительный метод применялся для определения разницы между ростом ВВП и другими экономическими показателями, производительностью секторов за тот же период. Определены меры правительства, направленные на поддержку предприятий и людей, пострадавших от пандемии.

\section{Распределение продовольствия}

Нарушение глобальных цепочек поставок продукции поставило в приоритет необходимость обеспечения продовольственной безопасности. Во многих странах правительства решают основную проблему обеспечения продуктами питания наиболее уязвимых групп населения, которые лишились основных доходов и привычных условий жизнедеятельности. Например, на сегодняшний день в Гондурасе правительство объявило, что основным приоритетом государства выступает производство продуктов питания, развитие сельского хозяйства и обеспечение продовольственной независимости и безопасности, осуществляется раздача продовольствия наименее обеспеченным группам населения. В Колумбии государство решает эту проблему путем организации на время пандемии доставки продуктов питания на дом, обеспечения отдельных категорий населения бесплатными обедами. Правительство Перу дополнительно профинансировало на муниципальном и региональном уровне обеспечение питанием социально незащищенных групп населения, расходование государственных средств на эти цели проходит тщательную проверку. В США действует программа «Школьные обеды по время пандемии COVID-19»: предоставляется питание для детей и подростков до 18 лет из малообеспеченных семей в период летних каникул [4]. 


\section{Выплата социальных пособий и поддержка занятости населения}

Основным приоритетом национальных и международных усилий стала поддержка занятости населения и бизнеса (табл. 1), а также возмещение потерянных доходов в форме социальных выплат по безработице, компенсаций и льгот работодателям, послаблений в налоговом регулировании. Например, в Германии правительство объявило, что если гражданин с инвалидностью получает пособие по болезни или безработице, то он также может с 27 апреля 2020 г. получить временную двухнедельную надбавку. В Корее пожилые работники получили право на субсидию для поддержки трудоустройства.

Таблища 1. Меры поддержки бизнеса и занятости в наибольшей степени пострадавших от ограничительных мер [5]

Table 1. Business and employment support measures most affected by restrictive measures [5]

\begin{tabular}{|c|c|c|c|c|c|c|c|c|c|}
\hline \multirow[t]{2}{*}{ Страна/Country } & \multicolumn{4}{|c|}{ Бизнес/Business } & \multicolumn{5}{|c|}{ Занятость/Employment } \\
\hline & 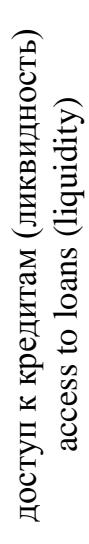 & 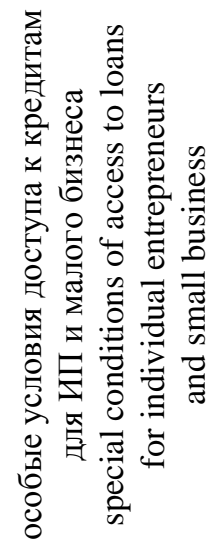 & 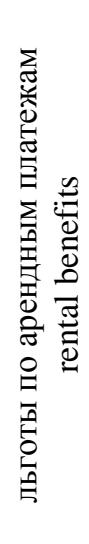 & 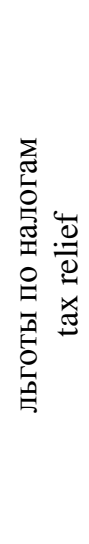 & 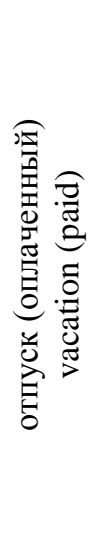 & 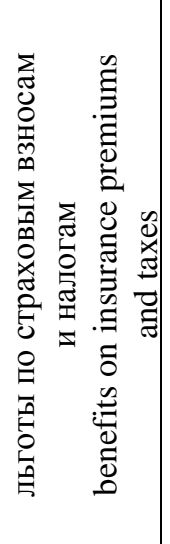 & 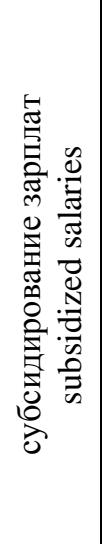 & 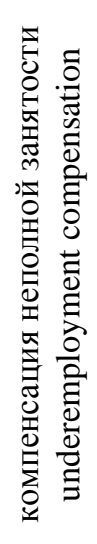 & 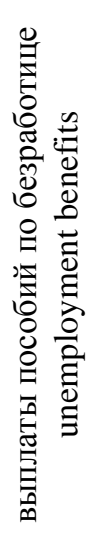 \\
\hline $\begin{array}{l}\text { Великобритания } \\
\text { Great Britain }\end{array}$ & $\checkmark$ & $\checkmark$ & & $\checkmark$ & & & $\checkmark$ & & \\
\hline $\begin{array}{l}\text { Германия } \\
\text { Germany }\end{array}$ & $\checkmark$ & $\checkmark$ & & $\checkmark$ & & $\checkmark$ & $\checkmark$ & $\checkmark$ & $\checkmark$ \\
\hline Испания/Spain & $\checkmark$ & $\checkmark$ & & $\checkmark$ & $\checkmark$ & $\checkmark$ & & $\checkmark$ & $\checkmark$ \\
\hline $\begin{array}{l}\text { Казахстан Ка- } \\
\text { zakhstan }\end{array}$ & & $\checkmark$ & & $\checkmark$ & & & $\checkmark$ & $\checkmark$ & $\checkmark$ \\
\hline Китай/China & & & & & & $\checkmark$ & $\checkmark$ & & \\
\hline США/USA & $\checkmark$ & $\checkmark$ & & $\checkmark$ & $\checkmark$ & $\checkmark$ & & & $\checkmark$ \\
\hline Франция/France & $\checkmark$ & & $\checkmark$ & & & $\checkmark$ & $\checkmark$ & $\checkmark$ & $\checkmark$ \\
\hline Италия/Italy & & $\checkmark$ & & $\checkmark$ & $\checkmark$ & $\checkmark$ & $\checkmark$ & $\checkmark$ & $\checkmark$ \\
\hline Япония/Japan & $\checkmark$ & $\checkmark$ & & & & $\checkmark$ & $\checkmark$ & $\checkmark$ & \\
\hline Корея/Korea & & $\checkmark$ & $\checkmark$ & & & $\checkmark$ & $\checkmark$ & $\checkmark$ & $\checkmark$ \\
\hline Россия/Russia & & $\checkmark$ & & $\checkmark$ & & $\checkmark$ & $\checkmark$ & $\checkmark$ & $\checkmark$ \\
\hline
\end{tabular}

В России во время пандемии выросло пособие по безработице до 12,1 тыс. руб. В столице положено выплатить 4000 руб. пенсионерам, в Московской области размер помощи составит 3000 руб., в других регионах России материальная помощь устанавливается локальными распорядительными документами [6, 7]. Также изменилось увеличение выплат по больничным листам в расчете за месяц, который предполагает не меньше минимального размера оплаты труда. Принят закон об автоматических выплатах на детей до 16 лет без подачи заявления до 1 марта 2021 г. Семьи, которые в момент пандемии оказались «в затруднительном материальном положении из-за временной по- 
тери работы», имеют возможность получить адресные пособия и выплаты, в том числе на детей (от 3 до 7 лет), без учета дохода за прошлый период. Выплаты производятся исходя из доходов семьи на момент подачи заявления, что может поддержать людей, пострадавших от массовых увольнений на предприятиях (в частности, в сферах услуг) в период пандемии.

Пандемия оказывает негативное влияние на финансирование пенсионных систем во всех странах. Ухудшение экономической ситуации, а именно сокращение рабочих мест, снижение реального размера заработной платы приводят к сужению базы для уплаты страховых пенсионных взносов. В рамках антикризисных мер в период пандемии многими странами были приняты решения о дополнительном увеличении объема пенсионных выплат. Например, Франция на время пандемии приостановила пенсионную реформу. Временное послабление ввели на уплату или снижение тарифов страховых взносов, которые включают взносы на пенсионное обеспечение. Например, временная приостановка уплаты страховых взносов для наиболее пострадавших предприятий (особенно это касается индивидуальных предпринимателей) предусмотрена в Испании, Италии, Франции, Корее, Китае, Японии, Казахстане [8].

\section{Создание условий для снижения риска заражения инфекцией в условиях ограничений}

Помимо финансовой поддержки, многие государства уделяют особое внимание вопросу психологической помощи лицам, которые вынуждены находиться в режиме изоляции из-за возраста или хронических заболеваний и для которых режим изоляции является дополнительным фактором риска бытового насилия и исключения из социума. Например, правительством Великобритании отдельное внимание уделяется мерам психологической поддержки людей старших поколений и вынужденной самоизоляции. В частности, в руководстве по социальному дистанцированию прописан вопрос, который посвящен психическому благополучию с предусмотренной онлайн-поддержкой. В Южной Корее предлагают персонализированные услуги для того, чтобы помочь справиться с психологическим давлением и стрессом в условиях пандемии. Пожилым людям, живущим в одиночестве, предоставляют наборы для выращивания бобов. В Панаме открыта телефонная линия психологической помощи, где люди получают консультацию психиатров, психологов и других специалистов. В Уругвае образован специальный Совет по недопущению роста случаев бытового насилия в отношении женщин и детей, пожилых людей, внесены необходимые дополнения в порядок работы медицинских служб и полиции.

В ряде стран (Швеция, Литва, Россия и др.) пандемия способствовала установлению сотрудничества (интеграции) между правительственными структурами и неправительственными организациями, волонтерами, работающими с пожилыми людьми (доставка продуктов, рецептов лекарств) [9].

В целях минимизации риска распространения инфекции и необходимости соблюдать самоизоляцию в европейских странах введена дополнительная социальная поддержка, которая предоставляется бездомным. Например, в Великобритании выделили из бюджета 4 млрд долл. США на обеспечение режима самоизоляции бездомных и возмещение средств, потраченных на организацию ночлега для них. В Колумбии предложили решить проблему переполненности тюрем путем расселения заключенных в незадействованные инфраструктурные объекты и отели [9].

Страны, затронутые пандемией коронавируса, потратили огромные суммы на предотвращение и общественный контроль, поддержку не только населения, но и пред- 
приятий. Ресурсы, мобилизованные ООН по состоянию на 3 сентября 2020 года, составляют 2,48 млрд долл. США, согласно Гуманитарному плану глобального реагирования, а потребности в ресурсах - 10,31 млрд долл. США [10].

Международный валютный фонд опубликовал прогноз экономических потерь от пандемии в виде изменения роста валового внутреннего продукта (ВВП) (табл. 2).

Таблища 2. Прогнозы экономического роста МВФ на 2020-2021 г2. по странам: реальный ВВП [11]

Table 2. IMF economic growth projections for 2020-2021 by country: real GDP [11]

\begin{tabular}{|l|c|c|c|}
\hline \multirow{2}{*}{\multicolumn{1}{c|}{ Страна/Country }} & \multicolumn{2}{c|}{ Реальный BВП/Real GDP } \\
\cline { 2 - 4 } & & \multicolumn{2}{c|}{$\begin{array}{c}\text { Прогнозные значения } \\
\text { Forecast values }\end{array}$} \\
\cline { 3 - 4 } & & 2020 & 2021 \\
\hline Северная Америка/North America & 2,0 & $-6,0$ & 4,5 \\
\hline $\begin{array}{l}\text { Ближний Восток и Центральная Азия } \\
\text { Middle East and Central Asia }\end{array}$ & 1,2 & $-2,8$ & 4,0 \\
\hline ввропа/Europe & 1,6 & $-6,6$ & 4,5 \\
\hline $\begin{array}{l}\text { Paзвивающаяся и развитая Европа } \\
\text { Developing and developed Europe }\end{array}$ & 2,1 & $-5,2$ & 4,2 \\
\hline Азия/Asia & & 0,0 & 7,6 \\
\hline Вьетнам/Vietnam & 4,6 & 2,7 & $-7,0$ \\
\hline Россия/Russia & 7,0 & $-5,6$ & 3,8 \\
\hline
\end{tabular}

Воздействие пандемии на жизнь общества и мировую экономику является плохо предсказуемым. К концу июня 2020 г. МВФ сделал дополнительный прогноз, согласно которому пандемия нанесла более масштабный ущерб, чем ожидалось. Мировая экономика сократится на $4,9 \%$, что хуже ожидаемого спада на $3 \%$, прогнозируемого в апреле 2020 г. К концу 2021 г. пандемия будет стоить мировой экономике 12,5 трлн долл. США в виде потерянного производства [12].

Распространение пандемии коронавируса мультиплицируется за счет свободной торговли и массовых путешествий по странам. Экономическая интеграция усилила трансграничное воздействие эпидемии, поскольку она создает взаимозависимость между экономиками в глобальных цепочках поставок в отношении сырья, комплектующих изделий, оборудования, потребительских товаров и импорта-экспорта. Социальное дистанцирование, практикуемое в различных странах и регионах, страдающих от пандемии и временной остановки поставщиков, перевозчиков или производителей, нарушает деятельность других, что приводит к снижению спроса, покупательной способности потребителей, увеличению безработицы, разрушению систем обслуживания и взаимодействия [13]. Термин «цепочки поставок» использовался в соответствующей концепции управления цепочек поставок, представленной консультантами в 1980-х годах. Цепочка поставок состоит из всех сторон, прямо или косвенно вовлеченных в выполнение запроса клиента. С. Чопра и П. Майндл, И.В. Козленкова и ряд других авторов, изучая концепцию системы управления цепочками поставок, пришли к выводу, что коммерция цепочек поставок - это система организаций, людей, видов деятельности, информации и ресурсов, участвующих в поставке продукта или услуги потребителю. Она включает в себя не только производителя и поставщиков, но и области маркетинговых каналов, логистики, закупок, взаимоотношений с конечными потребителями, связи фирм с конечными потребителями $[14,15]$. Сбои в работе цепочки поставок, вызванные закрытием производственной площадки, могут иметь эффект домино, который сокращает объем производства других компаний, что, в свою очередь, может повлиять на большее 
количество компаний. Поскольку производственный процесс был наиболее частым местом серьезных нарушений и, скорее всего, мешал другим нарушениям, которые распространялись во многих направлениях. Этот эффект «домино» быстро распространяется как внутри страны, так и из одной страны в другую.

Таким образом, пандемия вызывает сбои в работе рынка и цепочки поставок во всех секторах экономики в глобальном масштабе. В работе И.И. Мухина и др. говорится, что в России неопределенность в период пандемии вызвала быстрый отток капитала, что привело к резкому падению цен на рынках и быстрому снижению обменных курсов. Безработица в России в 2020 г. станет максимальной с 2011 г. и вырастет до $5,7 \%$. Согласно прогнозам, уровень безработицы начнет снижаться: в 2021 г. он составит 5,4 \%, в 2022 г. $-4,9 \%$, в 2023 г. - 4,7\% [16].

Е.В. Максимова, А.Г. Рябцев, О.А. Сазонова, анализируя влияние пандемии на экономику России, приходят к выводу, что снижение экономического роста и изменения в социальной жизни различных слоев населения сильно повлияли на социальноэкономическое развитие России. Ежеквартальная статистика показывает, что последствия пандемии сказываются на многих сферах жизни в худшую сторону [17]. Выделено 9 отраслей, которые больше всех пострадали от ухудшения экономической ситуации и нуждаются в государственной поддержке: культура, организация досуга и развлечений; физкультурно-оздоровительная деятельность и спорт; авиаперевозки, аэропорты, автоперевозки; деятельность туристических агентств и прочих организаций, предоставляющих услуги в сфере туризма; гостиничный бизнес; общепит; организации дополнительного образования, негосударственные образовательные учреждения; организация конференций и выставок; предоставление бытовых услуг населению. В число предложенных мер вошли создание антикризисного фонда на 300 млрд руб., налоговые льготы для туроператоров и авиакомпаний, а также отмена ограничений для транспорта торговых сетей в городах.

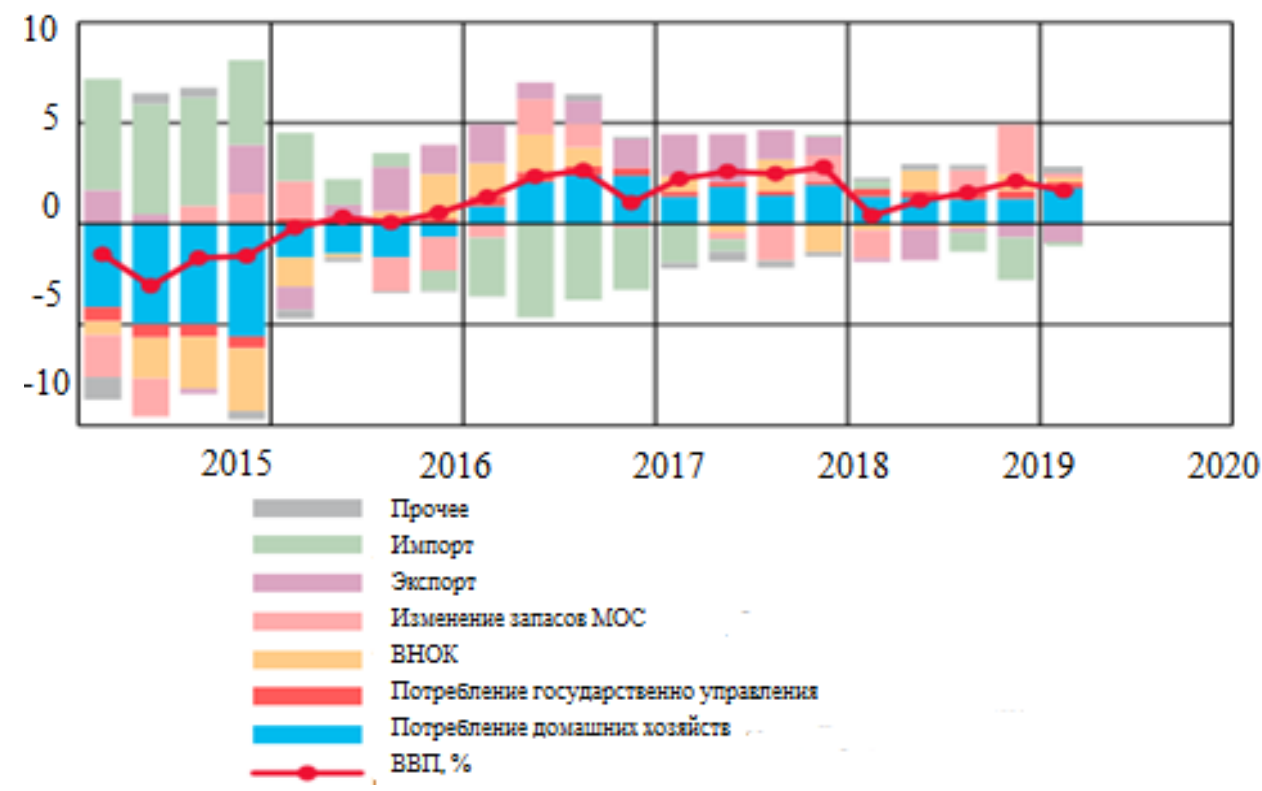

Рисунок. ВВП России [18]

Figure. GDP of Russia [18]

Отмечено, что в июне 2020 г. деловая активность в российской экономике начала восстанавливаться. Бюджетные меры поддержки домохозяйств, корпоративного секто- 
ра и отложенный спрос способствовали росту потребительской активности и восстановлению инвестиционного спроса. Но на рынке труда продолжали сохраняться неблагоприятные тенденции, что свидетельствует о его наибольшей уязвимости. Неполное снятие ограничений на работу предприятий в сфере услуг и снижение доходов, малый внешний спрос продолжает сдерживать восстановление деловой активности в течение 2020 г., что способствует уменьшению спроса в экономике [18].

Из приведенных данных на рисунке видно, что годовое снижение ВВП в 2020 г. в целом может составить 9-10 \%. Выявлено множество причин, которые негативно повлияли на ВВП. Наиболее значимыми являются: падение потребления домохозяйств, которое вызвало снижение доходов в условиях ограничений деловой активности; снижение экспорта, обусловленное ослаблением внешнего спроса и исполнением договоренностей ОПЕК. Напротив, положительное влияние на внутренний спрос оказали бюджетные меры, направленные на поддержку домохозяйств и корпоративного сектора [18]. Они способствовали смягчению ограничений и создали условия для расширения экономической активности. Однако годовые темпы экономического роста во втором полугодии остались отрицательными и по итогам 2020 г. снизились на 4,5-5,5\%.

\section{таблица 3. Динамика основных экономических показателей, отражающая рынок труда 2019-2020 г2. [18]}

Table 3. Dynamics of the main economic indicators reflecting the labor market 2019-2020 [18]

\begin{tabular}{|l|c|c|c|}
\hline \multicolumn{1}{|c|}{ Показатели/Indicators } & 2019 & 2020,1 кв. & 2020,2 кв. \\
\hline $\begin{array}{l}\text { Уровень безработицы, NS/SA (\% от рабочей силы) } \\
\text { Unemployment rate, NSA/SA (\% of labor force) }\end{array}$ & 4,6 & 4,6 & 6,0 \\
\hline Номинальная заработная плата/Nominal wages & 9,5 & 8,8 & - \\
\hline Реальная заработная плата/Real wages & 4,8 & 6,2 & - \\
\hline
\end{tabular}

На фоне частичного снятия ограничительных мер и возвращения к производственной деятельности снижение потребности работодателей в работниках замедлилось, особенно это касается людей пенсионного возраста. Для поддержки работников государство ввело субсидии на выплату заработной платы с целью поддержки занятости. Уровень безработицы повысился до 6,3 \%. Численность безработных за месяц увеличилась на 0,1 млн человек [18].

В мае 2020 г. рост номинальной заработной платы повысился до $4 \%$, этот рост рассматривается как временный. Низкая годовая инфляция способствовала росту заработной платы на 1 \%, который произошёл за счет государственной поддержки медицинским работникам и смены сезонности части выплат в добыче полезных ископаемых. Например, в Томской области стимулирующие выплаты составили от 25 до 80 тыс. руб. Существенное снижение заработных плат по-прежнему наблюдалось в отраслях сферы услуг (гостиницы и рестораны, культура и спорт). Реальные располагаемые денежные доходы населения снизились на $8 \%$. Наиболее заметно пострадали предпринимательские и прочие доходы. Обязательные платежи внесли положительный вклад в динамику доходов, это связано со снижением налогооблагаемой базы и отсрочкой уплаты авансовых платежей для индивидуальных предпринимателей. Значительную поддержку доходам оказали антикризисные выплаты из бюджета (около 0,8 трлн руб., или $6 \%$ всех доходов) [19].

И.В. Логунцова подчеркивает, что социальное дистанцирование, ограничение иммиграции и другие превентивные меры, применяемые во многих странах мира, в том числе в России, приводят к сокращению числа иностранных туристов. Падение оборота 
сферы туризма достигло 95-100 \%, а объем недополученных доходов уже превысил 1,5 трлн руб. из-за ограничений, введенных в рамках борьбы с пандемией. В результате этого спада ряд отелей и ресторанов обанкротились или временно закрылись, а сотни тысяч рабочих остались без работы или частично заняты [20]. В связи с этим готовится программа по выводу туристской сферы из экономического кризиса, определяются основные направления деятельности по стабилизации этой отрасли: поэтапный план по выходу из ограничительных мер с учетом новых требований на период пандемии безопасности туристов и сохранение привлекательности туристского продукта; налоговые льготы (уменьшение НДС, освободить от уплаты налогов); поддержка инвесторов и собственников туристской инфраструктуры (субсидирование процентных ставок на строительство туристской инфраструктуры, выдача беспроцентных кредитов); доступность и расширение внутреннего предложения путем разработки новых региональных продуктов; субсидирование путешествий для социально незащищенных групп граждан; продвижение доступного отдыха в России с помощью цифрофизации туристских услуг в регионах страны.

Сокращение спроса как на внутреннем, так и на мировом рынках вынуждают многие предприятия прекратить работу и уволить работников. В настоящее время нет точных прогнозов относительно временных рамок и последствий пандемии, но ее последствия будут ощущаться еще долгое время. Таким образом, устойчивость производственного сектора и экономики в целом должна постоянно поддерживаться. Следовательно, в дальнейшем макроэкономическая политика России должна быть сосредоточена:

1) на продолжении противоэпидемических мероприятий и помощи пострадавшим предприятиям и людям;

2) сосредоточении внимания на развитии связанных и поддерживающих отраслей, рассматривая это как стратегию импортозамещения и ключ к достижению целей развития вспомогательной промышленности на 2016-2025 гг., что приведет к привлечению внутренних поставщиков, стимулированию внутреннего производства;

3) поощрении роста производительности, основанного на внутреннем спросе, наряду с моделью роста, ориентированного на экспорт, поскольку условия для поддержки роста экспорта для развивающихся стран исчерпаны из-за воздействия колебаний, связанных с пандемией;

4) росте доходов граждан, восстановлении занятости, перезапуске инвестиционного цикла, запуске новых режимов занятости и снятии барьеров цифровизации для лиц старших возрастных групп;

5) повышении осведомленности владельцев бизнеса о продвижении инновационной деятельности, усилении цифровой трансформации для достижения целей устойчивого развития и построении устойчивого бизнеса.

Однако проблемы, связанные с падением сферы услуг, могут привести к диверсификации бизнеса и структурным изменениям, обусловленным цифровизацией экономической деятельности. Например, туристические и гостиничные услуги переориентируются на внутренний туризм для путешественников всех возрастных групп в долгосрочной перспективе.

\section{Заключение}

Воздействие пандемии COVID-19 в целом приводит к потерям и нарушениям социально-экономического развития и благополучия. Для восстановления экономической активности и вовлеченности наиболее уязвимых групп населения в социум правитель- 
ство предложило пакет спасательных работ для предприятий и оказание финансовой социальной помощи пострадавшим от эпидемии.

Пандемия обнажает недостатки в производственных системах и социальном управлении, но также создает новые возможности в качестве платформы для дальнейшего социально-экономического развития. На макроуровне определены новые сильные стороны для включения в политику развития, направленную на предотвращение и контроль пандемии, пересмотр налоговой нагрузки, преодоление кризиса и содействие социально-экономическому развитию в будущем.

Анализ показал, что многие страны не разрабатывают, а опираются на уже существующие социальные программы, которые временно видоизменяют на период действия пандемии. Говорить об оценке эффективности принимаемых странами антикризисных мер, особенно в отношении уязвимых слоев населения, еще рано, но можно уже сказать, что опыт выхода из кризиса свидетельствует о важности и быстрой реакции стран на данный кризис.

Результаты данного исследования имеют важное значение в части проектирования целей и инструментов государственной политики в отношении уязвимых слоев населения в период пандемии.

Исследование выполнено при финансовой поддержке РФФИ в рамках научно-исследовательского проекта «Разработка комплексной оценки эффективности вовлеченности пожилых людей в региональный социум», проект №19-010-00984.

\section{Список литературы}

1. Коронавирус в России - ситуация на 15 ноября 2020: сколько заболевших и умерших от КОВИД-19, последние новости. URL: https://koronavirustoday.ru/news/russia/koronavirus-v-rossii-situacziya-na-15noyabrya-2020/ (дата обращения 01.12.2020).

2. Daily news of epidemic situation // Ministry of Health. URL: https://www.moh.gov.sg/covid-19 (дата обращения 01.12.2020).

3. Видеообращение В. Путина на пленарном заседании юбилейной, 75-й сессии Генеральной Ассамблеи Организации Объединённых наций 22 сентября 2020 г. URL: http://kremlin.ru/events/ president/news/64074 (дата обращения 01.12.2020).

4. Социальные последствия пандемии COVID-19 и инклюзивность. URL: https://ach.gov.ru/upload/pdf/ Covid-19-inclusion.pdf (дата обращения 01.12.2020).

5. Covid-19 и международная практика поддержки экономики и населения. Меры поддержки бизнеса и занятости // Институт социальной политики НИУ ВШЭ. URL: https://isp.hse.ru/covid_ip (дата обращения 01.12.2020).

6. О введении режима повышенной готовности: указ мэра Москвы № 12-УМ от 05.03.2020 г. URL: http://base.garant.ru/73711482/ (дата обращения 12 September 2020).

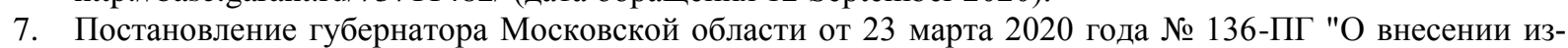
менений в постановление Губернатора Московской области от 12.03.2020 № 108-ПГ "О введении в Московской области режима повышенной готовности для органов управления и сил Московской областной системы предупреждения и ликвидации чрезвычайных ситуаций и некоторых мерах по предотвращению распространения новой коронавирусной инфекции (COVID-2019) на территории Московской области. URL: https://mosreg.ru/dokumenty/normotvorchestvo/prinyato-gubernatorom/ postanovleniya/23-03-2020-08-59-40-postanovlenie-gubernatora-moskovskoy-oblasti-ot-23 (дата обращения 12.09.2020).

8. Обзор Фонда Росконгресс об антикризисных мерах: лучшие мировые практики. URL: https://roscongress.org/upload/medialibrary/6c4/Obzor-Fonda-Roskongress-ob-antikrizisnykhmerakh_luchshie-mirovye-praktiki_23.04.2020.pdf (дата обращения 01.12.2020).

9. COVID-19 и социальная политика в отношении граждан старшего поколения: обзор мер, принятых зарубежными странами с различным уровнем развития. URL: https://www.hse.ru/data/ 2020/07/12/1595800002/ISP\%20HSE_COVID-19\%20and\%20Elderly\%20-\%20Internati..ussion\%20Paper \%205_July\%2007\%202020_RUS.pdf (дата обращения 01.12.2020). 
10. Комплексное реагирование системы Организации Объединенных наций на COVID-19: спасение людей, защита общества, более эффективное восстановление. URL: https://www.un.org/sites/un2.un.org/ files/un_comprehensive_response_to_covid19_russian.pdf (дата обращения 29.11.2020).

11. World Economic Outlook, April 2020: The Great Lockdown // IMF. - 2020. URL: https://www.imf.org/en/ Publications/WEO/Issues/2020/04/14/weo-april-2020 (дата обращения 29.11.2020).

12. Binh Dao Thanhl, Barysheva G.A., Ngoc Tran Thi Bich. The impact of the COVID-19 pandemic on socioeconomic development: a case study of tourism services, textile and garment industry in Vietnam // Proceedings of the Research Technologies of Pandemic Coronavirus Impact (RTCOV 2020). Advances in Social Science, Education and Humanities Research. - 2020. - V. 486. - P. 439-446. URL: https://www.atlantis-press.com/proceedings/rtcov-20/125945716 (дата обращения 29.11.2020).

13. Lynch D.J. IMF says global economic collapse caused by coronavirus will be even worse than feared // The Washington Post. - June 25, 2020. URL: https:/www.washingtonpost.com/business/2020/06/24/imf-globaleconomy-coronavirus/ (дата обращения 29.11.2020)

14. Chopra S., Meindl P. Supply chain management: strategy, planning, and operation. - Upper Saddle River: Pearson Prentice Hall, 2007. - 552 p.

15. The role of marketing channels in supply chain management / I.V. Kozlenkova, G. Tomas, M. Hultb, D.J. Lund, J. Menad, P. Kekec // Journal of Retailing. - 2015. - V. 91 (4). - P. 586-609. DOI: https://doi.org/10.1016/j.jretai.2015.03.003

16. Мухина И.И., Синдяшкина Е.Н. Занятость и безработица: кризис или новые возможности. Социально-трудовые исследования. - 2020. - № 40 (3). - С. 56-67. DOI: 10.34022/2658-3712-2020-40-3-56-67.

17. Максимова Е.В., Рябцев А.Г., Сазонова О.А. Влияние коронавируса на экономику России // Инновации и инвестиции. - 2020. - № 4. - С. 283-286.

18. Экономика. Информационно-аналитический комментарий. - 2020. - № 6 (54). URL: https://www.cbr.ru/Collection/Collection/File/29098/EC_2020-06.pdf (дата обращения 29.11.2020).

19. Занятость и безработица в Российской Федерации в августе 2020 года (по итогам обследования рабочей силы). URL: https://rosstat.gov.ru/bgd/free/B04_03/IssWWW.exe/Stg/d05/181.htm (дата обращения 29.11.2020).

20. Логунцова И.В. Индустрия туризма в условиях пандемии коронавируса: вызовы и перспективы // Государственное управление. Электронный вестник. - 2020. - № 80. - С. 49-65. URL: https://cyberleninka.ru/article/n/industriya-turizma-v-usloviyah-pandemii-koronavirusa-vyzovy-iperspektivy/viewer (дата обращения 29.11.2020).

Поступила 02.12.2020 2. 


\title{
IMPACT OF THE COVID-19 PANDEMIC ON SOCIAL AND ECONOMIC DEVELOPMENT AND THE SITUATION OF THE MOST VULNERABLE POPULATION
}

\author{
Galina A. Barysheva ${ }^{1}$, \\ f ganb@tpu.ru \\ Olga A. Antipanova1, \\ antipanova2020@gmail.com \\ Binh Dao Thanh', \\ ngoc.tranthibich@hust.edu.vn \\ 1 National Research Tomsk Polytechnic University, \\ 30, Lenin avenue, Tomsk, 634050, Russia. \\ 2 Hanoi University of Science and Technology Dai Co Viet, \\ 1, Dai Co Viet street, Ha Noi, 00084, Vietnam.
}

Galina A. Barysheva, Dr. Sc., professor, leader of International Scientific Educational Laboratory for the Improvement of Wellbeing Technologies of Older Adults, National Research Tomsk Polytechnic University.

Olga A. Antipanova, postgraduate student, laboratory assistant, International Scientific Educational Laboratory for the Improvement of Wellbeing Technologies of Older Adults, National Research Tomsk Polytechnic University.

Binh Dao Thanh, PhD., associate professor, Hanoi University of Science and Technology Dai Co Viet.

The article provides an overview and analysis of the economic consequences for economic agents of the outbreak of the COVID-19 pandemic and its impact on the socio-economic development of the Russian Federation. The purpose of this study is the need to change markets in the context of unpredictable socio-economic fluctuations in the world and the long-term consequences of the pandemic for people, including the elderly. Methods. the method of descriptive statistics was used on samples of predicted values of economic losses from a pandemic in the form of changes in the growth of gross domestic product published by the International Monetary Fund (2020). Russian statistical and periodic sources were used. The comparative method was used to determine the difference between gross domestic product growth and other economic indicators over the same period. Data synthesis and analysis methods were applied to clarify the status and interdependence of industries and services of global markets in globalization using empirical research on this topic. Results. The authors have identified the financial measures aimed at supporting enterprises and organizations, as well as the most vulnerable categories of the population. The main measures taken are: food distribution, payment of social benefits, support for new employment regimes, medical care, creating conditions to reduce the risk of infection. At the macro level, new strengths of the carried out actions were identified for inclusion them in development policies aimed at preventing and controlling a pandemic, revising the tax burden, overcoming the crisis and promoting socio-economic development in the future.

Key words: COVID-19 pandemic, relief measures, vulnerable groups of the population, supply chain, labor market, unemployment, wages, social benefits, vulnerable populations, older adults.

The study was carried out with the financial support of the Russian Foundation for Basic Research within the framework of the research project «Development of a comprehensive assessment of the effectiveness of the involvement of older people in the regional society», project no. 19-010-00984. 


\section{REFERENCES}

1. Koronavirus v Rossii sityatsia na 15 noyabrya 2020: skolko zabolevshikh $i$ umershikh ot KOVID-19, poslednie novosti [Coronavirus in Russia today, November 15, 2020: how many cases and deaths from COVID-19, the latest news]. Available at: https://koronavirustoday.ru/news/russia/koronavirus-v-rossiisituacziya-na-15-noyabrya-2020/ (accessed 12 January 2020).

2. Daily news of epidemic situation. Ministry of Health. Available at: https://www.moh.gov.sg/covid-19 (accessed 1 December 2020).

3. Videoobrashchenie V. Putina na plenarnom zasedanii yubileynoy, 75-y sessii Generalnoy Assamblei Organizatsii Obedinonnykh Natsiy 22 sentyabrya $2020 \mathrm{~g}$. [Video message from V. Putin at the plenary meeting of the $75^{\text {th }}$ session of the General Assembly of the United Nations on September 22, 2020]. Available at: http://kremlin.ru/events/president/news/64074 (accessed 12 January 2020).

4. Sotsialnye posledstviya pandemii COVID-19 i inklyuzivnost [Social consequences of the COVID-19 pandemic and inclusiveness]. Available at: https://ach.gov.ru/upload/pdf/Covid-19-inclusion.pdf (accessed 1 December 2020).

5. Covid-19 i mezhdunarodnaya praktika podderzhki ekonomiki i naseleniya. Mery podderzhki biznesa i zanyatosti [Covid-19 and international practice of supporting the economy and population. Business and employment support measures]. Institute for Social Policy, National Research University Higher School of Economics. Available at: https://isp.hse.ru/covid_ip (accessed 12 January 2020).

6. O vvedenii rezhima povyshennoy gotovnosti [On the introduction of high alert].Ukaz mera Moskvy № 12-UM ot 05.03.2020 g. [Decree of the Mayor of Moscow No. 12-UM dated 05.03.2020]. Available at: http://base.garant.ru/73711482/ (accessed 12 September 2020).

7. On amendments to the Decree of the Governor of the Moscow Region dated 12.03.2020 No. 108-PG «On the introduction in the Moscow Region of a high alert regime for the authorities and forces of the Moscow Regional Emergency Prevention and Response System and some measures to prevent the spread of a new coronavirus infection (COVID 2019) on the territory of the Moscow region». Postanovlenie gubernatora № 136-PG of 23.03.2020 g. [Resolution of the Governor No. 136-PG dated 23.03.2020]. Available at: https://mosreg.ru/dokumenty/normotvorchestvo/prinyato-gubernatorom/postanovleniya/23-03-2020-08-5940-postanovlenie-gubernatora-moskovskoy-oblasti-ot-23 (accessed 12 September 2020).

8. Obzor Fonda Roskongress ob antikrizisnykh merakh: luchshie mirovye praktiki [Review of the Roscongress Foundation on anti-crisis measures: the best world practices]. Available at: https://roscongress.org/upload/medialibrary/6c4/Obzor-Fonda-Roskongress-ob-antikrizisnykhmerakh_luchshie-mirovye-praktiki_04/23/2020.pdf (accessed 1 December 2020).

9. COVID-19 i sotsialnaya politika $v$ otnoshenii grazhdan starshego pokoleniya: obzor mer, prinyatykh zarubezhnymi stranami s razlichnym urovnem razvitiya [COVID-19 and social policy towards older citizens: an overview of measures taken by foreign countries with different levels of development]. Available at: https://www.hse.ru/data/2020/07/12/1595800002/ISP\%20HSE_COVID-19\%20and\%20Elderly\%20\%20Internati.ussion\%20Paper\%205_July\%2007\%202020_RUS.pdf (accessed 1 December 2020).

10. Kompleksnoe reagirovanie sistemy Organizatsii Obyedinennykh natsiy na COVID-19: spasenie lyudey, zashchita obshchestva, bolee effektivnoe vosstanovlenie [Comprehensive response of the United Nations system to COVID-19: saving people, protecting society, more effective recovery]. OON. Available at: https://www.un.org/sites/un2.un.org/files/un_comprehensive_response_to_covid19_russian.pdf (accessed 29 November 2020).

11. World Economic Outlook, April 2020: The Great Lockdown. IMF. 2020. Available at: https://www.imf.org/en/Publications/WEO/Issues/2020/04/14/weo-april-2020 (accessed 29.11.2020).

12. Binh Dao Thanh1, Barysheva G.A., Ngoc Tran Thi Bich. The impact of the COVID-19 pandemic on socioeconomic development: a case study of tourism services, textile and garment industry in Vietnam. Proceedings of the Research Technologies of Pandemic Coronavirus Impact (RTCOV 2020). Advances in Social Science, Education and Humanities Research, 2020, vol. 486, pp. 439-446. Available at: https://www.atlantis-press.com/proceedings/rtcov-20/125945716 (accessed 29 November 2020).

13. Lynch D.J. IMF says global economic collapse caused by coronavirus will be even worse than feared. The Washington Post. June 25, 2020. Available at: https://www.washingtonpost.com/business/2020/06/24/imfglobal-economy-coronavirus/ (accessed 29 November 2020).

14. Chopra S., Meindl P. Supply chain management: strategy, planning, and operation. Upper Saddle River, Pearson Prentice Hall, 2007. 552 p.

15. Kozlenkova I.V., Tomas G., Hultb M., Lund D.J., Menad J., Kekec P. The role of marketing channels in supply chain management. Journal of Retailing, 2015, vol. 91 (4), pp. 586-609. DOI: https://doi.org/10.1016/j.jretai.2015.03.003 
16. Mukhina I.I., Sindyashkina E.N. Zanyatost i bezrabotitsa: krizis ili novye vozmozhnosti [Employment and unemployment: crisis or new opportunities]. Sotsialno-trudovye issledovaniya, 2020, no. 3 (40), pp. 56-67. DOI: 10.34022/2658-3712-2020-40-3-56-67.

17. Maksimova E.V., Ryabtsev A.G., Sazonova O.A. Vliyanie koronavirusa na ekonomiku Rossii [Impact of coronavirus on the Russian economy]. Innovatsii i investitsii, 2020, no. 4, pp. 283-286.

18. Ekonomika. Informatsionno-analiticheskiy kommentariy [Economy. Information and analytical commentary]. 2020, no. 6 (54). Available at: https://www.cbr.ru/Collection/Collection/File/29098/EC_2020-06.pdf (accessed 29 November 2020).

19. Zanyatost $i$ bezrabotitsa $v$ Rossiyskoy Federatsii $v$ avguste 2020 goda (po itogam obsledovaniya rabochey sily) [Employment and unemployment in the Russian Federation in August 2020 (based on the labor force survey)]. Available at: https://rosstat.gov.ru/bgd/free/B04_03/IssWWW.exe/Stg/d05/181.htm (accessed 29 November 2020).

20. Loguntsova I.V. Industriya turizma v usloviyakh pandemii koronavirusa: vyzovy i perspektivy [The tourism industry in the context of the coronavirus pandemic: challenges and prospects]. Gosudarstvennoye upravlenie. Elektronny vestnik, 2020, no. 80, pp. 49-65. Available at: https://cyberleninka.ru/article/n/industriyaturizma-v-usloviyah-pandemii-koronavirusa-vyzovy-i-perspektivy/viewer (accessed 29 November 2020).

Received: 2 December 2020. 